\title{
Editorial
}

\section{Earth Observation for Ecosystems Monitoring in Space and Time: A Special Issue in Remote Sensing}

\section{Duccio Rocchini}

Department of Biodiversity and Molecular Ecology, Research and Innovation Centre, Fondazione Edmund Mach, Via E. Mach 1, 38010 S. Michele all'Adige (TN), Italy;

E-Mail: ducciorocchini@gmail.com or duccio.rocchini@fmach.it

Academic Editor: Prasad S. Thenkabail

Received: 15 June 2015 / Accepted: 16 June 2015 / Published: 18 June 2015

\begin{abstract}
This Editorial introduces the papers published in the special issue "Earth Observation for Ecosystems Monitoring in Space and Time" which includes the most important researchers in the field and the most challenging aspects of the application of remote sensing to study ecosystems.
\end{abstract}

Keywords: forests; marine ecosystems; modeling techniques; remote sensing; terrestrial ecosystems

\section{Introduction: Why a Special Issue on Earth Observation for Ecosystems Monitoring in Space and Time?}

Nowadays, a number of different sensors are available for studying ecosystems from space. This allows researchers to study ecosystems at a number of spatial scales (considering both grain and extent) with a high temporal resolution.

Further, ecological theory has been applied to remote sensing data to monitor species dispersal and diversity over space and time. Ecosystem-based models have also been developed to monitor, at a high temporal resolution, Earth surface changes over large areas. The need for high temporal resolution for studying global and local changes is directly related to the use of techniques other than field-based monitoring. Consequently, remote sensing is critical for ecosystems monitoring.

Remote sensing and ecosystems monitoring challenges include (i) scale issues, (ii) data gathering and analysis, and (iii) software development. 


\section{The Value of the Special Issue}

The published special issue represents a stimulating discussion concerning innovative techniques/approaches that are based on remote sensing data, which are used for the study of ecosystems at different spatial and temporal scales. Research scientists and other subject matter experts submitted innovative and challenging papers that showed advances in several topics: estimating the spatial distribution of plant species richness by Light Detection and Ranging (LiDAR) and hyperspectral data [1], assessing habitat quality of forest corridor based on NDVI [2], applying remote sensing to study (marine) coral ecosystems [3], identifying ecosystem functional types [4], distinguishing between different forest trunk size classes from remote sensing [5], detecting changes in forest patterns [6], applying light use efficiency models to estimate vegetation productivity [7], classifying grassland successional stages by airborne hyperspectral images [8], proposing monitoring programs of grasslands based on multi-temporal optical and radar satellite images [9], estimating the potential of remote sensing to capture field-based plants phenology [10].

\section{Special Issue Main Topics and Advancements}

Based on the abstracts of the 10 published papers, Figure 1 represents the major themes of such manuscripts. Although forest habitats were mostly studied (e.g. [1,2,5,6]), also marine ecosystems were considered in the special issue as a core part of remote sensing use in ecology [3]. Very different remote sensing data, including optical and LiDAR data, were used, applying a variety of interesting models (Figure 1), from dynamic system models for phenology assessment [10] to light use efficiency models for inferring gross primary production [7] to modified random clustering to represent forest fragmentation [6].

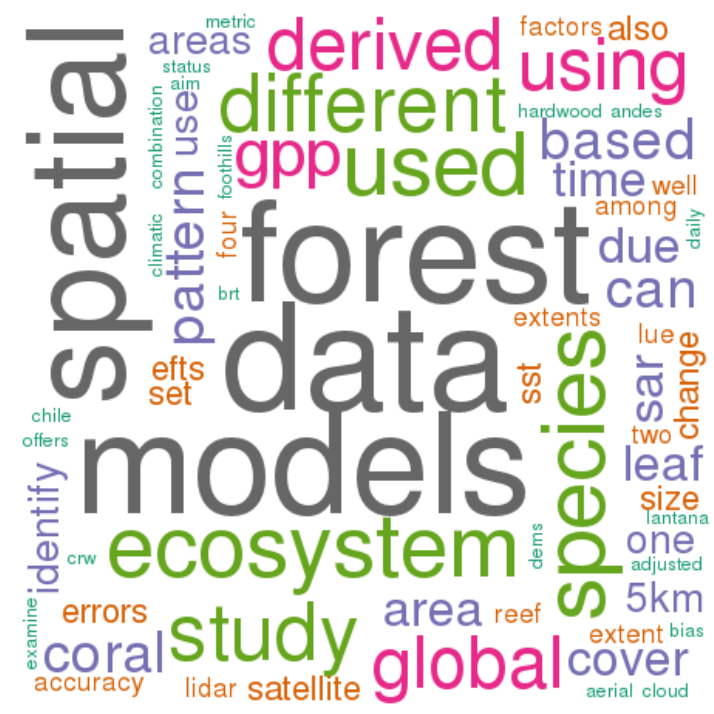

Figure 1. Cloud of the words contained in the abstracts of the special issue "Earth Observation for Ecosystems Monitoring in Space and Time”. The bigger the size, the higher the frequency of each word. The code and the set needed to produce the cloud are available in the Supplementary material. 
The 50 researchers coming from nine countries (Figure 2) did extend the current knowledge on remote sensing applied to ecosystem monitoring based on previous literature which was fully brought up. Major challenges related to hot themes and topics deriving from previous remote sensing literature (cited in the published manuscripts of this special issue) were seriously faced, applying a remote perspective mostly to vegetation data analysis at the landscape scale, under global change (Figure 3).

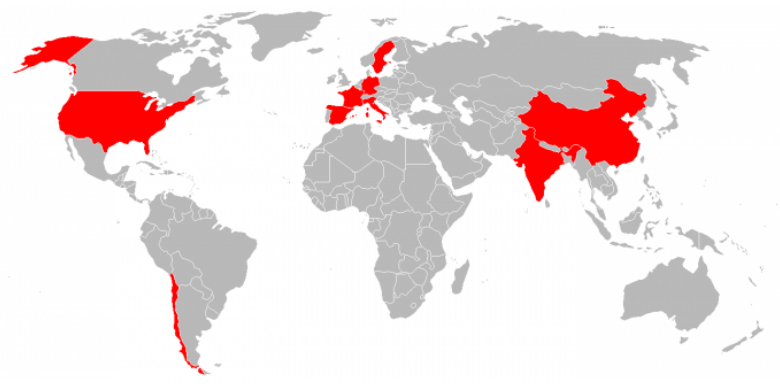

Figure 2. The nine different countries involved in the special issue.

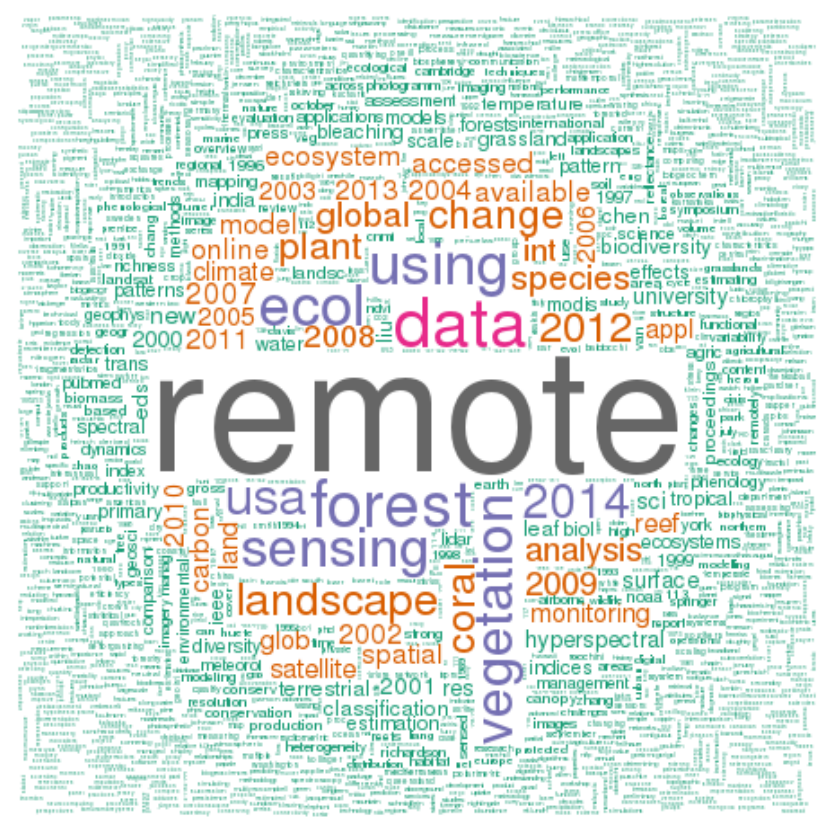

Figure 3. Cloud of the words contained in the references of the papers of the special issue "Earth Observation for Ecosystems Monitoring in Space and Time". The bigger the size, the higher the frequency of each word. The code and the set needed to produce the cloud are available in the Supplementary material.

\section{Conclusion}

Large-scale field sampling of several ecological parameters is challenging considering sampling efforts and costs [11]. However, as demonstrated in this special issue, there are available remote sensing tools - including data and advanced modeling techniques — which may allow ecologists to obtain ecological information in a timely manner with a certain degree of confidence. In this special issue, such approaches were described in detail to disentangle problems and issues related to the application of remote sensing in ecology and to face current challenges related to an effective monitoring of ecosystems in space and time. 


\section{Acknowledgments}

Duccio Rocchini is partially funded by: (i) the EU BON (Building the European Biodiversity Observation Network) project, funded by the European Union under the 7th Framework programme, Contract No. 308454, (ii) the ERA-Net BiodivERsA, with the national funders ANR, BelSPO and DFG, part of the 2012-2013 BiodivERsA call for research proposals, (iii) the ICT COST Action TD1202 "Mapping and the citizen sensor", funded by the European Commission.

\section{Conflicts of Interest}

The author declares no conflict of interest.

\section{References}

1. Ceballos, A.; Hernández, J.; Corvalán, P.; Galleguillos, M. Comparison of Airborne LiDAR and Satellite Hyperspectral Remote Sensing to Estimate Vascular Plant Richness in Deciduous Mediterranean Forests of Central Chile. Remote Sens. 2015, 7, 2692-2714.

2. Mallegowda, P.; Rengaian, G.; Krishnan, J.; Niphadkar, M. Assessing Habitat Quality of Forest-Corridors through NDVI Analysis in Dry Tropical Forests of South India: Implications for Conservation. Remote Sens. 2015, 7, 1619-1639.

3. Liu, G.; Heron, S.F.; Eakin, C.M.; Muller-Karger, F.E.; Vega-Rodriguez, M.; Guild, L.S.; De La Cour, J.L.; Geiger, E.F.; Skirving, W.J.; Burgess, T.F.R.; et al. Reef-Scale Thermal Stress Monitoring of Coral Ecosystems: New 5-km Global Products from NOAA Coral Reef Watch. Remote Sens. 2014, 6, 11579-11606.

4. Pérez-Hoyos, A.; Martínez, B.; García-Haro, F.J.; Moreno, Á.; Gilabert, M.A. Identification of Ecosystem Functional Types from Coarse Resolution Imagery Using a Self-Organizing Map Approach: A Case Study for Spain. Remote Sens. 2014, 6, 11391-11419.

5. Al-Hamdan, M.; Cruise, J.; Rickman, D.; Quattrochi, D. Forest Stand Size-Species Models Using Spatial Analyses of Remotely Sensed Data. Remote Sens. 2014, 6, 9802-9828.

6. Frate, L.; Saura, S.; Minotti, M.; Di Martino, P.; Giancola, C.; Carranza, M.L. Quantifying Forest Spatial Pattern Trends at Multiple Extents: An Approach to Detect Significant Changes at Different Scales. Remote Sens. 2014, 6, 9298-9315.

7. Cai, W.; Yuan, W.; Liang, S.; Liu, S.; Dong, W.; Chen, Y.; Liu, D.; Zhang, H. Large Differences in Terrestrial Vegetation Production Derived from Satellite-Based Light Use Efficiency Models. Remote Sens. 2014, 6, 8945-8965.

8. Möckel, T.; Dalmayne, J.; Prentice, H.C.; Eklundh, L.; Purschke, O.; Schmidtlein, S.; Hall, K. Classification of Grassland Successional Stages Using Airborne Hyperspectral Imagery. Remote Sens. 2014, 6, 7732-7761.

9. Dusseux, P.; Corpetti, T.; Hubert-Moy, L.; Corgne, S. Combined Use of Multi-Temporal Optical and Radar Satellite Images for Grassland Monitoring. Remote Sens. 2014, 6, 6163-6182.

10. Xu, H.; Twine, T.E.; Yang, X. Evaluating Remotely Sensed Phenological Metrics in a Dynamic Ecosystem Model. Remote Sens. 2014, 6, 4660-4686. 
11. Rocchini, D.; Foody, G.M.; Nagendra, H.; Ricotta, C.; Anand, M.; He, K.S.; Amici, V.; Kleinschmit, B.; FÃûrster, M.; Schmidtlein, S.; et al. Uncertainty in ecosystem mapping by remote sensing. Comput. Geosci. 2013, 50, 128-135.

(c) 2015 by the author; licensee MDPI, Basel, Switzerland. This article is an open access article distributed under the terms and conditions of the Creative Commons Attribution license (http://creativecommons.org/licenses/by/4.0/). 